\title{
Total right ventricular exclusion procedure: An operation for isolated congestive right ventricular failure
}

Shunji Sano, $\mathrm{MD}^{\mathrm{a}}$

Kozo Ishino, MDa

Masaaki Kawada, MD

Shingo Kasahara, $\mathrm{MD}^{\mathrm{a}}$

Takushi Kohmoto, MDa

Mamoru Takeuchi, MD ${ }^{\mathrm{b}}$

Shin-ichi Ohtsuki, MD ${ }^{\mathrm{c}}$

Sponsor: Roger B. B. Mee, MD

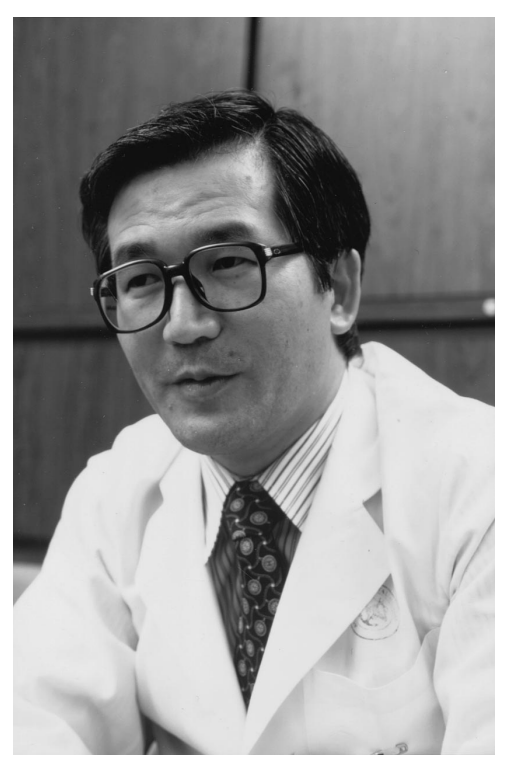

Dr Sano

From the Departments of Cardiovascular Surgery, ${ }^{\mathrm{a}}$ Anesthesiology, ${ }^{\mathrm{b}}$ and Pediatrics, ${ }^{\mathrm{c}}$ Okayama University Medical School, Okayama, Japan.

Read at the Eighty-first Annual Meeting of The American Association for Thoracic Surgery, San Diego, Calif, May 6-9, 2001.

Received for publication May 29, 2001; revisions requested July 12, 2001; revisions received Oct 3, 2001; accepted for publication Oct 8, 2001.

Address for reprints: Shunji Sano, MD, Department of Cardiovascular Surgery, Okayama University Medical School 2-5-1 Shikata-cho, Okayama-City 700-8558, Japan (E-mail: s_sano@cc.okayama-u.ac.jp).

J Thorac Cardiovasc Surg 2002;123:640-7

Copyright $(9) 2002$ by The American Association for Thoracic Surgery

0022-5223/2002 \$35.00+0 $\quad \mathbf{1 2 / 6 / 1 2 1 1 6 0}$

doi: $10.1067 / \mathrm{mtc} .2002 .121160$
Objective: To prevent possible deleterious effects of right ventricular volume overload on cardiorespiratory function, we developed a total right ventricular exclusion procedure for the treatment of end-stage isolated congestive right ventricular failure.

Methods: Since 1996, this procedure has been performed in 5 patients in New York Heart Association functional class IV: 2 adults with arrhythmogenic right ventricular dysplasia and 3 children with Ebstein anomaly. The entire right ventricular free wall was resected along the atrioventricular groove and then parallel to the interventricular septum, sparing the pulmonary valve and a skeletonized right coronary artery. The orifice of the tricuspid valve was closed with either a polytetrafluoroethylene patch or with its leaflets. The defect of the right ventricular free wall was covered with a polytetrafluoroethylene patch in the 2 patients with arrhythmogenic right ventricular dysplasia and directly closed with the remnant of the free wall in the 3 children with Ebstein anomaly. After resection of a redundant right atrial wall, coronary sinus blood flow was rerouted into the left atrium through an atrial septal defect. A total cavopulmonary connection was constructed in 4 patients and a bidirectional superior cavopulmonary anastomosis in 1 infant. The heart was controlled with a DDD pacemaker in 3 patients.

Results: The patients were extubated at a mean of 14 hours postoperatively (range, 1-38 hours). There were no early or late deaths. At follow-up, ranging from 8 to 57 months, the mean cardiothoracic ratio had decreased from $74 \% \pm 7 \%$ before the operation to $52 \% \pm 6 \%(P<.01)$. All patients are in functional class I. Neither of the patients with arrhythmogenic right ventricular dysplasia have had attacks of ventricular tachycardia nor are they using antiarrhythmic medication.

Conclusions: The total right ventricular exclusion procedure provides effective decompression of the lung, as well as the left ventricle, and may result in more effective volume loading of a surgically created single ventricle with increased systemic output. We believe that this new surgical option offers rescue treatment for isolated end-stage right ventricular failure in critically ill patients.

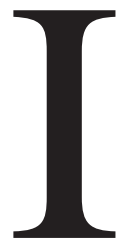

solated right ventricular dysfunction caused by myocardial diseases or long-lasting volume overload gradually results in right ventricular and right atrial dilatation, leading to fatal cardiorespiratory failure. Arrhythmogenic right ventricular dysplasia is a specific myocardial disease of unknown cause characterized by fatty and fibrofatty replacement of the right ventricular myocardium associated with life-threatening ventricular tachycardia., ${ }^{1,2}$ The tachycardia is often refractory to medical treatment. Nonpharmacologic thera- 
TABLE 1. Preoperative status and echocardiographic assessment in the 5 patients undergoing the total right ventricular exclusion procedure

\begin{tabular}{|c|c|c|c|c|c|}
\hline & \multicolumn{5}{|c|}{ Patient no. } \\
\hline & 1 & 2 & 3 & 4 & 5 \\
\hline History of CPR & + & + & + & + & + \\
\hline CTR & 66 & 70 & 74 & 84 & 77 \\
\hline Mechanical ventilation & + & - & + & - & + \\
\hline Inotropic support & + & - & + & + & + \\
\hline Tricuspid regurgitation & Severe & Severe & Severe & Severe & Severe \\
\hline Pulmonary regurgitation & None & Mild & Moderate & Severe & Moderate \\
\hline Mitral regurgitation & Moderate & None & None & Moderate & None \\
\hline Leftward shift of IAS & + & + & + & + & + \\
\hline Paradoxical motion of IVS & + & + & + & + & + \\
\hline
\end{tabular}

CPR, Cardiopulmonary resuscitation; CTR, cardiothoracic ratio; IAS, interatrial septum; IVS, interventricular septum.

pies, such as catheter ablation, ${ }^{3}$ implantation of an automatic implantable cardioverter-defibrillator, ${ }^{4}$ and surgical intervention to interrupt the re-entrant circuit, $, 5,6$ have been used. Because any area of the right ventricular myocardium is potentially arrhythmogenic, surgical isolation of the right ventricular free wall has been an effective treatment of multifocal or polymorphic ventricular tachycardia. ${ }^{7-9}$ However, only cardiac transplantation has been life saving for patients with severe right ventricular dysfunction caused by the frequent occurrence of ventricular tachycardia. ${ }^{10,11}$

We developed a total right ventricular exclusion procedure composed of resection of the entire right ventricular free wall and subsequent total cavopulmonary connection. This procedure was first performed in 1996 as rescue surgery for a moribund patient with arrhythmogenic right ventricular dysplasia. Indications for this procedure have extended to pediatric patients with an extremely enlarged nonfunctioning right ventricle associated with Ebstein anomaly of the tricuspid valve. In this article we describe the surgical techniques and early- to medium-term results of the total right ventricular exclusion procedure in 5 patients.

\section{Patients and Methods}

Between June 1996 and July 2000, the total right ventricular exclusion procedure was performed in 2 adults with arrhythmogenic right ventricular dysplasia and 3 children with Ebstein anomaly. Preoperative clinical data on the 5 patients are summarized in Table 1.

\section{Case Presentations}

Patient 1. A 27-year-old man first experienced syncope and ventricular tachycardia in December 1995 and was admitted to a local hospital, where he was given a diagnosis of arrhythmogenic right ventricular dysplasia on the basis of electrophysiologic and histologic studies. Because of failed catheter ablation, he was transferred to Okayama University Hospital for possible antiarrhythmic therapy on June 12, 1996. The electrocardiogram documented 5 distinct morphologies of ventricular tachycardia (rate, 110-120 beats/min) mixed with atrial tachycardia. Cardiac cath- eterization demonstrated a mean pulmonary artery pressure of 26 $\mathrm{mm} \mathrm{Hg}$ and a pulmonary capillary wedge pressure of $23 \mathrm{~mm} \mathrm{Hg}$. Endocardial mapping confirmed the earliest recorded activity for each morphology to be located in the right ventricular free wall. Over the next 2 weeks, cardiorespiratory failure developed as a result of recurrent ventricular tachycardia, and the patient subsequently required mechanical ventilation and intra-aortic balloon pumping. On June 24, however, systolic blood pressure dropped to less than $90 \mathrm{~mm} \mathrm{Hg}$, with right atrial pressure of $23 \mathrm{~mm} \mathrm{Hg}$, and the cardiac index progressively decreased to $1.3 \mathrm{~L} \cdot \mathrm{min}^{-1} \cdot \mathrm{m}^{-2}$; thus extracorporeal membrane oxygenation was established by means of femoral cannulation. Despite volume unloading on the right ventricle with extracorporeal membrane oxygenation, ventricular tachycardia and occasional ventricular fibrillation became refractory to cardioversion. On June 26, 1996, after 8 hours of sustained ventricular tachycardia, he was transferred to the operating room with maximal life-support systems and underwent the total right ventricular exclusion procedure.

Patient 2. A 44-year-old woman who underwent closure of an atrial septal defect at 8 years of age and tricuspid valve repair at 36 years of age first experienced ventricular tachycardia in 1991. After the initial episode, she was hospitalized 5 times for recurrent ventricular tachycardia and required cardioversion at least 6 times. At the time of referral in September 1997, she was cachectic as a result of protein-losing enteropathy and liver dysfunction. Cardiac catheterization showed a mean pulmonary artery pressure of 14 $\mathrm{mm} \mathrm{Hg}$. Echocardiography demonstrated an extremely dilated right ventricle with markedly diminished contractility, massive tricuspid regurgitation, and normal left ventricular function. Electrophysiologic study revealed a focus of ventricular tachycardia in the right ventricular free wall. Results of histologic examination led to the suspicion of arrhythmogenic right ventricular dysplasia. All possible surgical treatments, including redo tricuspid valve repair or replacement, implantation of a cardioverter-defibrillator, right ventricular isolation, and exclusion procedures, were proposed to the patient and her family. In consideration of ventricular tachycardia arising from the right ventricular myocardium, poor right ventricular function, and severe tricuspid regurgitation, we elected to perform the total right ventricular exclusion procedure, which was carried out on January 21, 1998. 


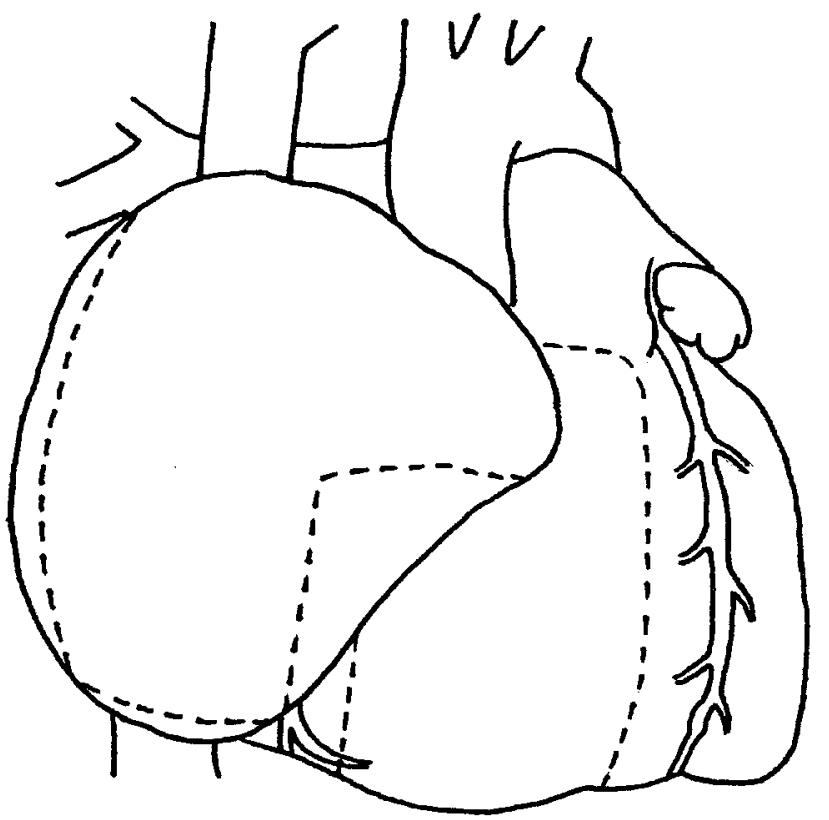

Figure 1. The right ventricular free wall was resected along the atrioventricular groove and then parallel to the interventricular septum, sparing the pulmonary valve and a skeletonized right coronary artery. The dotted lines show incisions for resection of the right ventricular free wall and the redundant right atrial wall.

Patient 3. A 14-month-old girl who had a factor VII coagulation defect was admitted to Okayama University Hospital on September 9, 1998, for surgical treatment of Ebstein anomaly. On admission, she had deep cyanosis, with an arterial oxygen tension of $30 \mathrm{~mm} \mathrm{Hg}$. Echocardiography revealed an atrial septal defect with a diameter of $7 \mathrm{~mm}$, Ebstein anomaly with severe tricuspid regurgitation, and moderate pulmonary regurgitation. A large atrialized right ventricle resulting from a 33-mm downward displacement of a dysplastic septal leaflet had a paper-thin noncontracting wall, whereas the small functional right ventricle had a systolic wall thickness of $2.4 \mathrm{~mm}$. She had a cerebral hemorrhage on September 11 and cardiac arrest on September 23. Because of recurrent cardiopulmonary collapse, she underwent an emergency operation on September 29, 1998.

Patient 4. A 5-year-old boy who was born with Ebstein anomaly and critical pulmonary stenosis underwent pulmonary valvotomy at 7 days of age and tricuspid valve repair and right ventricular outflow reconstruction with a monocusp-valved onlay patch at 1 year of age. Eight months later, he required a third operation, including tricuspid valve replacement and pacemaker implantation. At 5 years of age, he had severe congestive right ventricular failure, with the highest brain natriuretic peptide value being $1819 \mathrm{pg} / \mathrm{mL}$, which was treated with continuous infusion of dobutamine and phosphodiesterase inhibitor (olprinone). Echocardiography showed a dilated and poorly contracting right ventricle, a huge right atrium, severe tricuspid regurgitation with back flow reaching the hepatic vein, and severe pulmonary regurgitation. After 3 months of bed rest, he underwent a fourth operation on March 15, 2000.
Patient 5. A 5-month-old boy, weighing $5.5 \mathrm{~kg}$, had dyspnea and severe cyanosis on July 13, 2000. On admission to the hospital, systemic acidosis was present with a $\mathrm{pH}$ of 6.9. Mechanical ventilation and inotropic support were required to stabilize his cardiorespiratory condition. Echocardiography showed Ebstein anomaly with severe tricuspid regurgitation, a restrictive but patent foramen ovale, and moderate pulmonary regurgitation. The septal leaflet was greatly displaced into the right ventricular outflow tract at a distance of $3.8 \mathrm{~mm}$ from the pulmonary valve. Because the greater part of the right ventricular free wall was thin and atrialized, and the anterior leaflet was also displaced downward from the atrioventricular junction, we performed a univentricular palliation that incorporated total resection of the right ventricular free wall and bidirectional superior cavopulmonary anastomosis on July 17, 2000 .

\section{Operative Procedure}

Arrhythmogenic right ventricular dysplasia. Through a midline sternotomy, hypothermic cardiopulmonary bypass $\left(34^{\circ} \mathrm{C}\right)$ was commenced with bicaval and aortic cannulation. The right atrium was opened to drain coronary sinus flow into the bypass circuit. Keeping the heart beating, the entire right ventricular free wall, including the tricuspid valve apparatus, was excised as follows. A longitudinal right ventriculotomy was made in the anterior right ventricle parallel to the atrioventricular groove and then around the tricuspid anulus, sparing the skeletonized right coronary artery and its posterior interventricular branches (Figure 1). This incision was extended across the right ventricular outflow tract (leaving the pulmonary valve intact), down the anterior surface parallel to the interventricular septum, around the right ventricular apex onto the posterior wall, and to the level of the tricuspid anulus just to the right of the crux of the heart. Special care was taken to avoid injury to the left anterior descending coronary artery. Any hemorrhage from branches of the right coronary artery was effectively controlled with electrocautery. During the ventriculotomy, the sustained ventricular tachycardia abruptly terminated in patient 1 . After complete removal of the right ventricular free wall from the heart, the papillary muscles of the tricuspid valve and the septoparietal trabeculations were resected from the interventricular septum and the right ventricular apex.

The tricuspid valve orifice was closed with a 1-mm-thick polytetrafluoroethylene (PTFE) patch secured with continuous 4-0 polypropylene sutures. The membranous interventricular septum was left above the patch to avoid heart block (Figure 2). Several cryolesions were placed along the ventriculotomy for latent foci of ventricular tachycardia. The right atrial free wall was almost totally resected to prevent potential supraventricular tachyarrhythmia, ${ }^{1}$ leaving a small triangular flap of the wall attached to the atrioventricular groove. A 24-mm-diameter PTFE tube for a cavopulmonary connection was anastomosed to the inferior vena caval orifice. At this stage, the aorta was crossclamped, and cold blood cardioplegic solution was administered in patient 2, whereas the whole procedure was completed with the heart beating in patient 1 . An atrial septal defect was created, and the coronary sinus was roofed with the right atrial flap to reroute blood flow into the left atrium (Figure 3). The superior vena cava was transected and anastomosed to the upper surface of the right pulmonary artery. The aorta was declamped, and rewarming commenced. An 


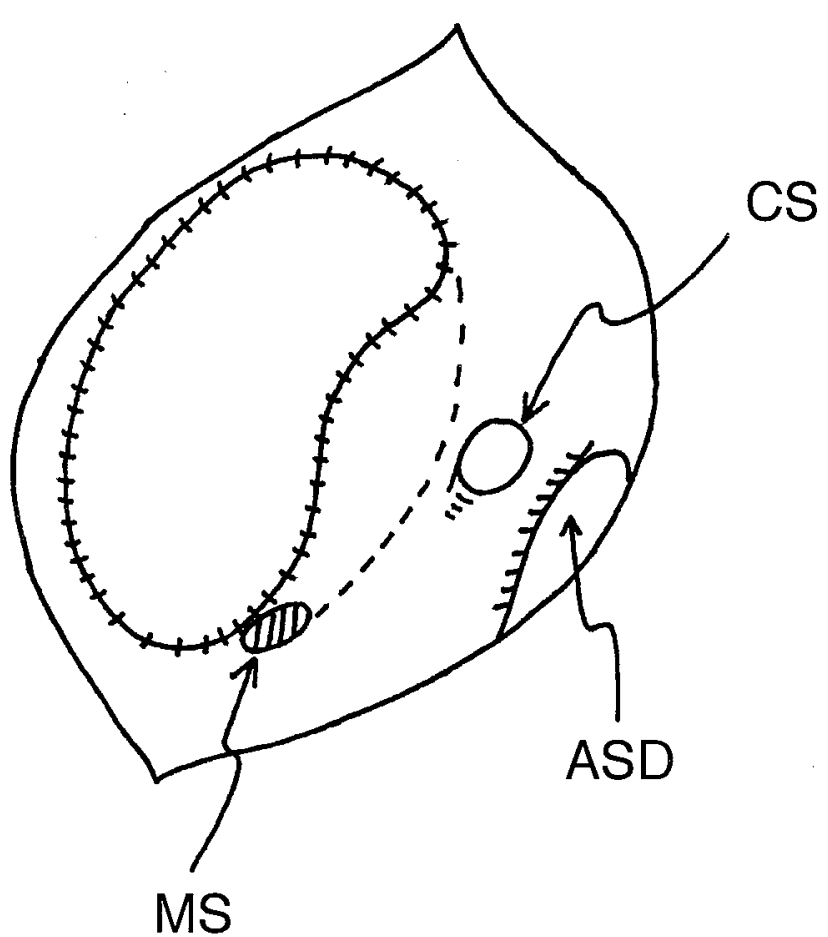

Figure 2. The tricuspid valve orifice was closed with a 1-mmthick PTFE patch secured with continuous 4-0 polypropylene sutures. The membranous interventricular septum was left above the patch to avoid heart block. ASD, Atrial septal defect; CS, coronary sinus; $M S$, membranous septum.

extracardiac total cavopulmonary connection was completed by anastomosing the distal end of the PTFE tube to the lower surface of the right pulmonary artery. A small communication between systemic and pulmonary venous returns was created with a 6-mm PTFE graft to preserve the ventricular preload while limiting an eventual rise in central venous pressure. Finally, the defect of the right ventricular free wall was covered with a small 1-mm-thick PTFE patch secured with continuous 4-0 polypropylene sutures (Figure 4). Unipolar epicardial pacing leads were placed on the left atrium and the left ventricle so that the heart could be controlled by a DDD pacemaker.

Ebstein anomaly. Three children underwent hypothermic cardiopulmonary bypass with bicaval and aortic cannulation. In patient 3, with an interatrial communication, the aorta was crossclamped, and crystalloid cardioplegia was infused. Heart beat was maintained in patients 4 and 5, with an intact atrial septum. After complete unloading of the right ventricle, the thin redundant right ventricular free wall was resected by incisions made 1 to $2 \mathrm{~cm}$ away from its attachment to the interventricular septum in these 3 patients. The pulmonary valve was closed in patients 3 and 4 and repaired in patient 5 . The tricuspid valve was partially excised, and its orifice was closed with a PTFE patch in patients 3 and 4, as described for patients with arrhythmogenic right ventricular dysplasia, and a 4-mm atrioventricular communication was created in the PTFE patch to drain blood through the Thebesian vein from a remnant right ventricle into the atrium. In patient 5 the tricuspid orifice was closed by suturing the anterior leaflet to the tricuspid

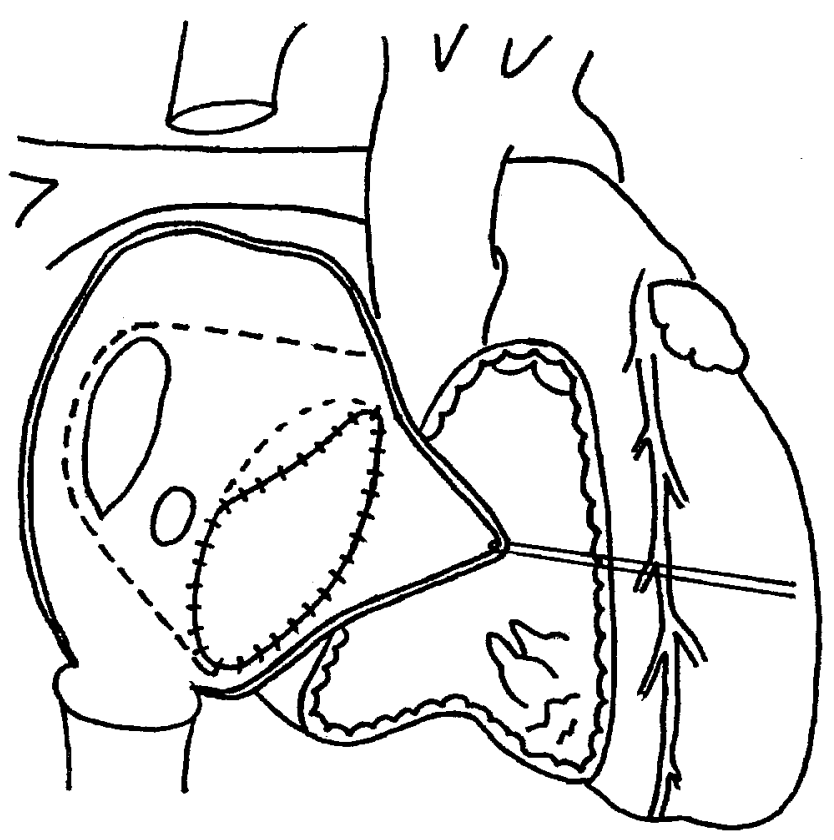

Figure 3. An atrial septal defect was created, and the coronary sinus was roofed with the right atrial flap to reroute blood flow into the left atrium. The dotted line indicates the suture line of the atrial flap to the interatrial septum.

anulus or to the displaced septal leaflet, thereby placing the membranous interventricular septum on the right atrial side. The defect of the right ventricle was directly closed with the remnant of the free wall by using a continuous polypropylene suture (Figure 5). Patients 4 and 5 underwent cardioplegic arrest at this point. The interatrial septum was resected, the redundant right atrial free wall was removed, and the atriotomy was closed. After aortic declamping, a total cavopulmonary connection was constructed with an inferior vena caval channel by using the right atrial wall ${ }^{12}$ in patient 3 and a 20-mm-diameter PTFE tube in patient 4. Bidirectional superior cavopulmonary anastomosis was performed in patient 5.

\section{Results}

Operative results are presented in Table 2. The patients were extubated between the 1st and 38th postoperative hour (mean, 14 hours), had a slow but uneventful recovery, and were discharged from the 25 th to 76 th postoperative day. There were no in-hospital or late deaths. At follow-up, ranging from 8 to 57 months (mean, 24 months), the mean cardiothoracic ratio decreased from the $74 \% \pm 7 \%$ preoperative value to $52 \% \pm 6 \%(P<.01$, Mann-Whitney test; Figure 6). Most recent echocardiography revealed no paradoxical motion of the interventricular septum and a left ventricular ejection fraction of greater than $60 \%$ in all patients.

Neither patient with arrhythmogenic right ventricular dysplasia has had an attack of ventricular tachycardia nor is receiving antiarrhythmic medication. At follow-up catheter- 


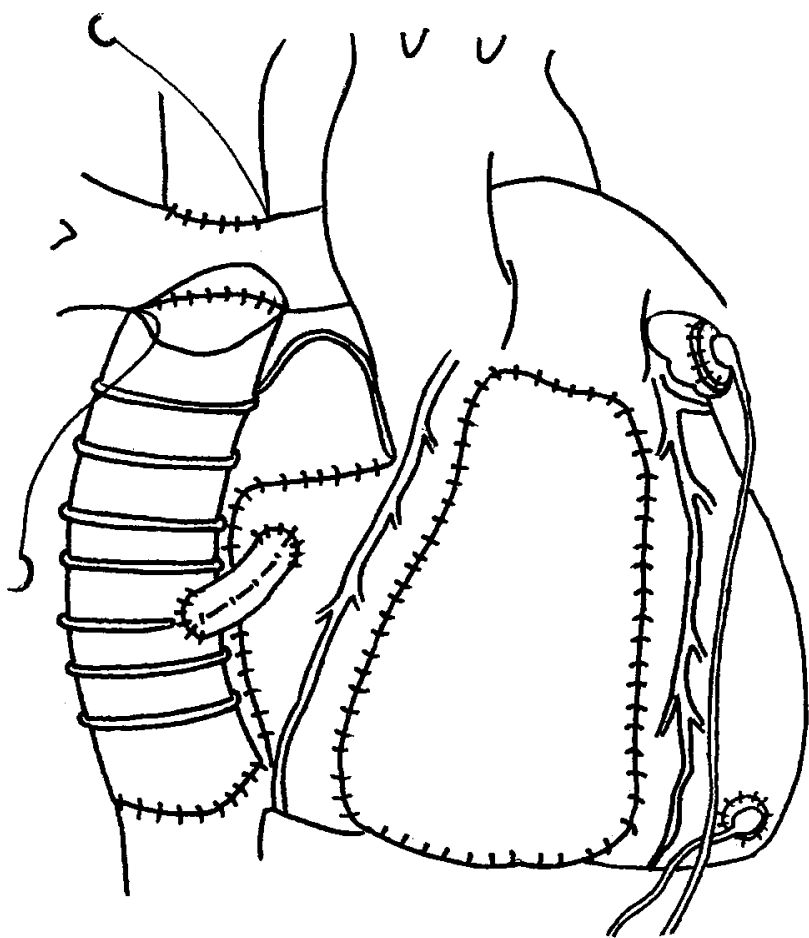

Figure 4. In patients with arrhythmogenic right ventricular dysplasia, a fenestrated extracardiac total cavopulmonary connection was constructed. The defect of the right ventricular free wall was covered with a small 1-mm-thick PTFE patch.

ization, central venous pressures were less than $15 \mathrm{~mm} \mathrm{Hg}$. The extracardiac cavopulmonary pathway and the skeletonized right coronary artery are demonstrated in Figure 7. Left ventricular function in patient 4 improved sequentially over the year after total right ventricular exclusion; ejection fraction evaluated with echocardiography was $38 \%$ at 1 month after the operation, 55\% at 6 months, and $62 \%$ at 1 year. All 5 patients are currently in New York Heart Association functional class I; patient 1 is employed in a fulltime job, patient 2 is a housewife, patient 3 is doing well without neurologic deficits, patient 4 is fully active and goes to kindergarten, and patient 5 is awaiting the Fontan procedure.

\section{Discussion}

Surgical treatment of arrhythmogenic right ventricular dysplasia has focused on the management of associated lifethreatening ventricular tachycardia. In 1983, Guiraudon and associates ${ }^{7}$ introduced an operation for complete isolation of multiple origins of ventricular tachycardia by disconnecting the entire right ventricular free wall. This procedure theoretically confines any arrhythmic activity arising from the diseased myocardium in the isolated right ventricular wall. Despite encouraging results, Cox and colleagues $^{8}$ and Nimkhedkar and coworkers ${ }^{9}$ warned against the routine use

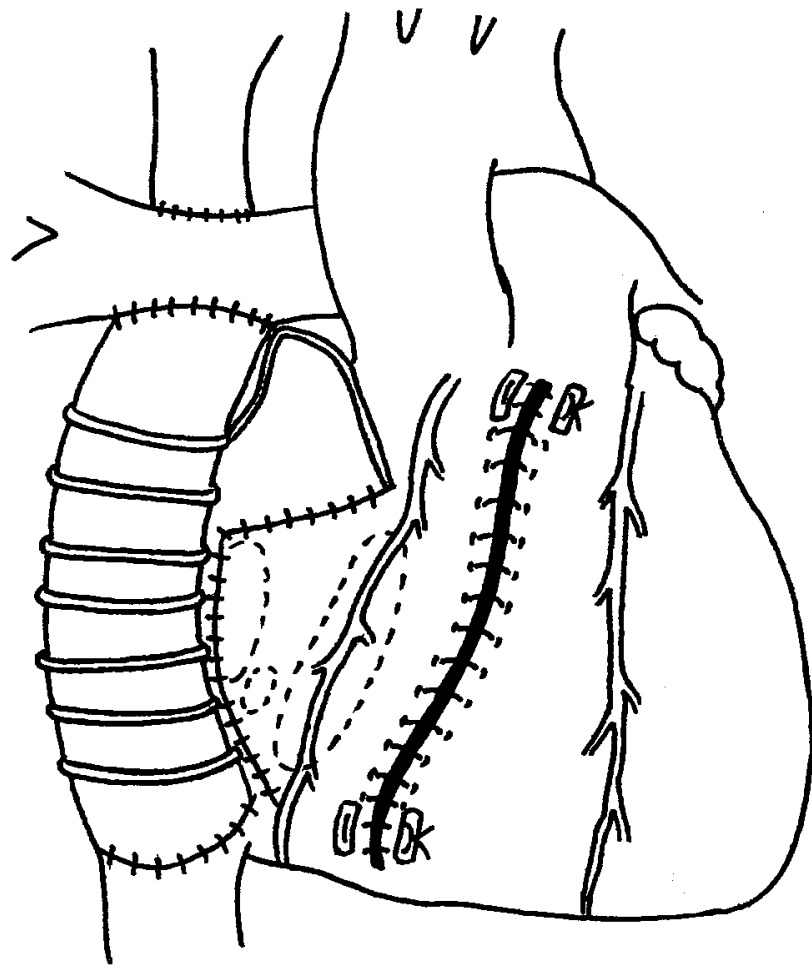

Figure 5. In children with Ebstein anomaly, the defect of the right ventricle was directly closed with the remnant of the free wall.

of the isolation procedure because of the high incidence of right ventricular failure. Our 2 patients with arrhythmogenic right ventricular dysplasia had intractable ventricular tachycardia, a markedly dilatated right ventricle, and severe tricuspid regurgitation. The resultant congestive right ventricular failure and the presence of tricuspid regurgitation precluded the indication for the isolation procedure. The only life-saving option for these patients appeared to be cardiac transplantation. We devised the operation as rescue surgery for a moribund patient on extracorporeal membrane oxygenation (patient 1). By resecting the diseased myocardium, creating a single left ventricle, and constructing a cavopulmonary connection, the total right ventricular exclusion procedure provided a definitive cure of end-stage right ventricular failure and refractory ventricular tachycardia associated with arrhythmogenic right ventricular dysplasia. This new surgical option should be indicated when the left ventricle, including the interventricular septum, is proved nonarrhythmogenic ${ }^{13}$ and functionally normal.

Ebstein anomaly is a spectrum of disease characterized by varying degrees of downward displacement of the septal and posterior leaflets of the tricuspid valve into the right ventricular cavity and marked dilatation of the anulus, resulting in tricuspid valve incompetence. ${ }^{14,15}$ The right ventricular myocardium is generally abnormal, with a decrease in the number of myocardial fibers. ${ }^{16}$ The results of ana- 


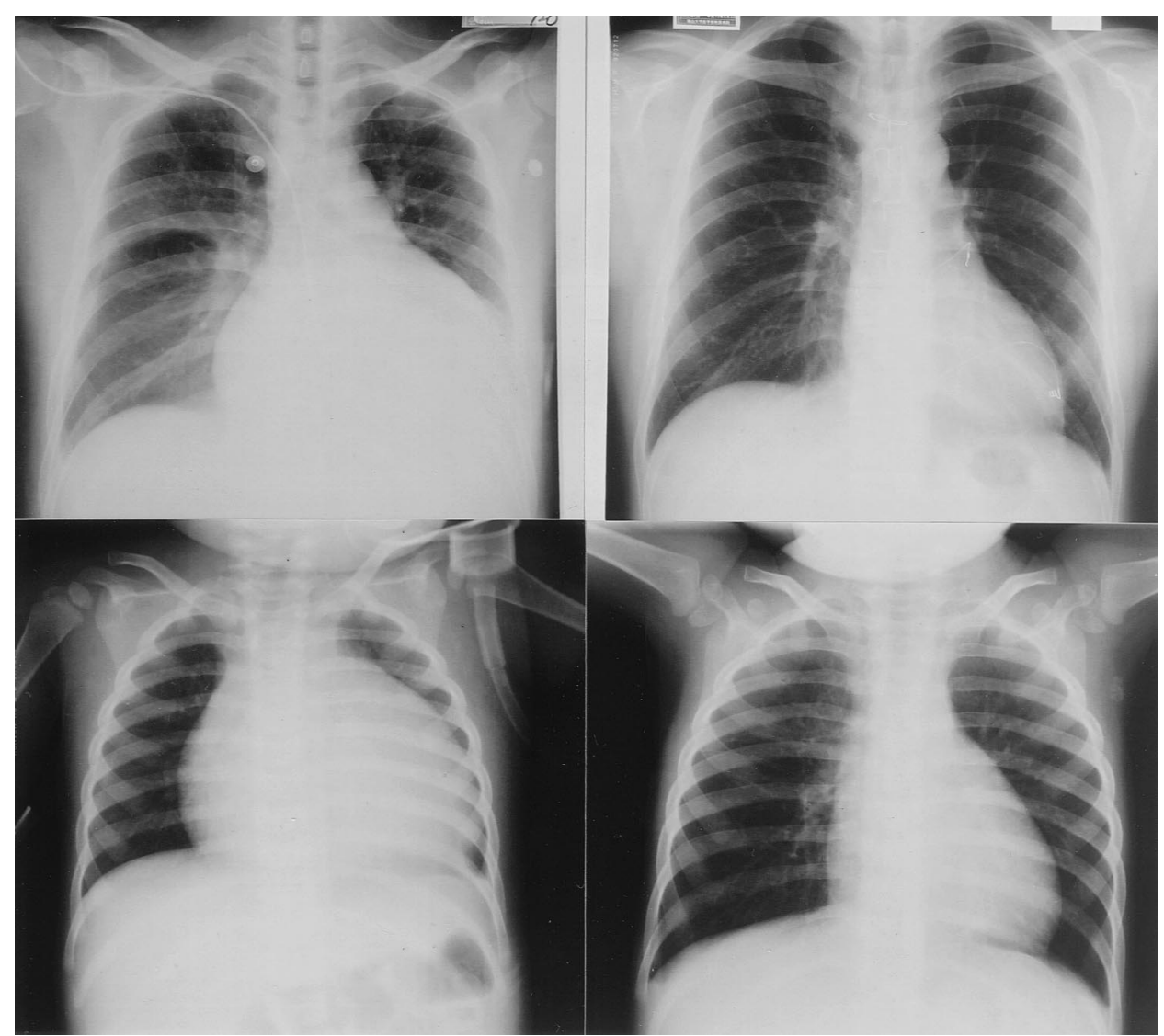

Figure 6. Chest roentgenograms of patient 1 with arrhythmogenic right ventricular dysplasia (top) and patient 3 with Ebstein anomaly (bottom) before the operation (left) and at the last follow-up (right).

TABLE 2. Operative results of the 5 patients undergoing the total right ventricular exclusion procedure

\begin{tabular}{lrrrrr}
\hline & \multicolumn{4}{c}{ Patient no. } \\
\cline { 2 - 5 } & $\mathbf{1}$ & $\mathbf{2}$ & $\mathbf{3}$ & $\mathbf{4}$ & $\mathbf{5}$ \\
\hline CPB time (min) & 198 & 234 & 144 & 190 & 102 \\
Aortic clamp time (min) & 0 & 21 & 82 & 16 & 2 \\
Intubation time (h) & 19 & 72 & 38 & 37 & 37 \\
Postoperative hospital stay (d) & 76 & Pacing & Sinus & Sinus & Sinus \\
Heart rhythm & Pacing & Pleural effusion & None & Pleural effusion & None \\
Complications & None & & &
\end{tabular}

$C P B$, Cardiopulmonary bypass.

tomic correction of this anomaly have improved in the last decades since tricuspid valve repair combined with ventriculoplasty by plication of the atrialized right ventricle ${ }^{17,18}$ has been performed in preference to valve replacement. Recent reports ${ }^{19,20}$ demonstrated beneficial effects of a bidirectional cavopulmonary connection in association with intracardiac repair on operative outcome and postoperative tricuspid valve function in patients with poor ventricular function.

Management of severe forms of Ebstein anomaly has remained a surgical challenge, particularly in symptomatic children presenting with congestive right heart failure and deep cyanosis. In 1991, Starnes and coworkers ${ }^{21}$ described an innovative univentricular palliation by creating a functional tricuspid atresia for critically ill neonates with this anomaly. Although the surgical concept of the right ventricular exclusion procedure described in this report is the same as that of Starnes' operation, our technique differs in some important ways. First, a large part of the right ventricular free wall is resected. Resultant volume reduction of the right ventricle promises normal interventricular motion, as evidenced in our patients. Second, the coronary sinus is 


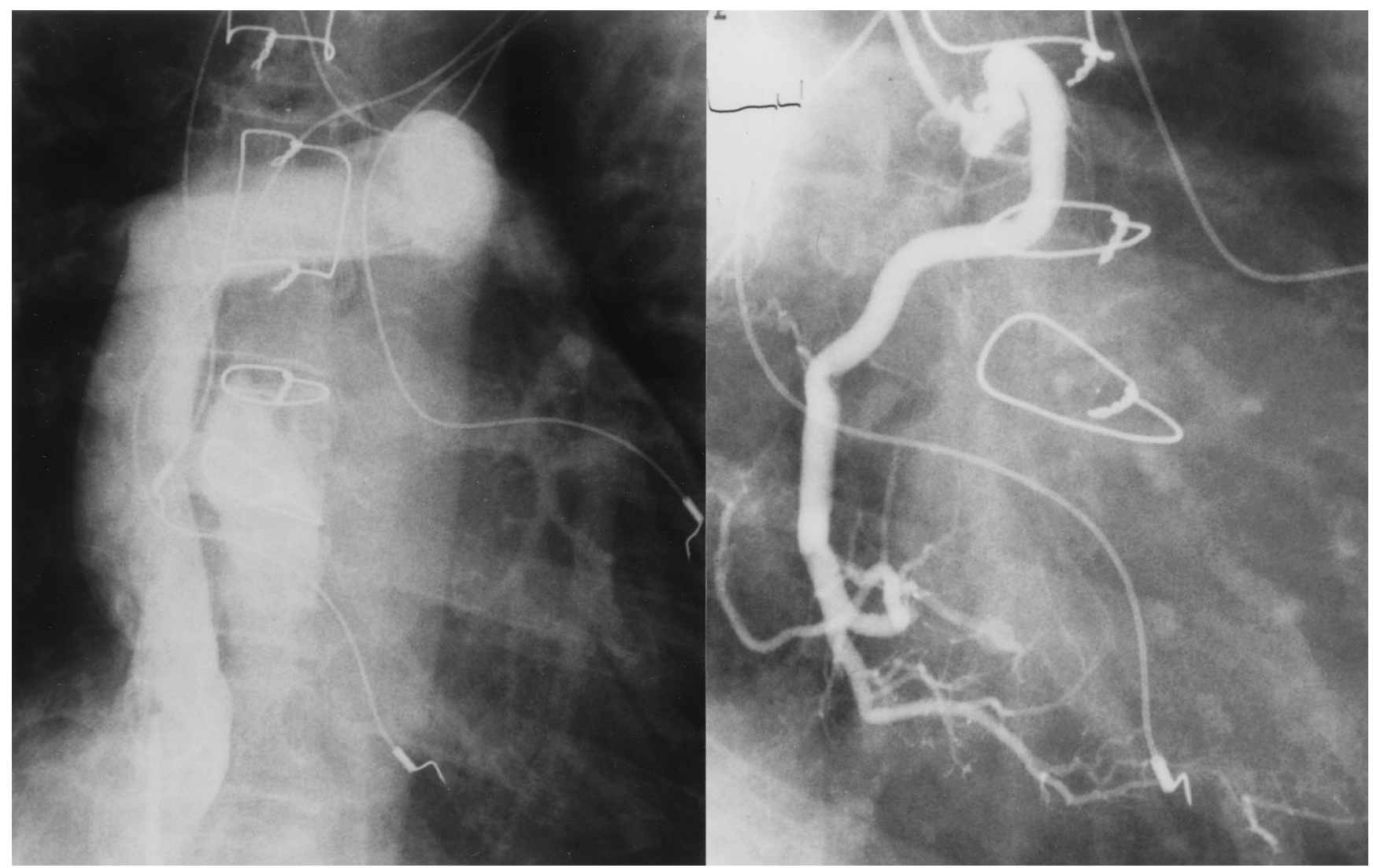

Figure 7. Angiograms 2 years after the total right ventricular exclusion procedure in patient 2 with arrhythmogenic right ventricular dysplasia, showing an inferior vena cava-pulmonary artery pathway with a patent fenestration (left) and skeletonized right coronary artery and intact posterior interventricular branches (right).

included in the atrium, whereas with the Starnes' technique, it is left on the ventricular side, thus requiring a functioning pulmonary valve. Finally, the tricuspid valve orifice is closed, leaving the membranous interventricular septum above the patch to reduce the risk of heart block. No definite statement can be made as yet concerning an indication for univentricular repair in this anomaly. Because repair of the tricuspid valve is the key to successful biventricular or one-and-a-half ventricular repair of Ebstein anomaly, particularly in the presence of pulmonary regurgitation, determination of operative procedure should be based on the exact assessment of right ventricular function and the surgeon's skill in repairing the tricuspid valve.

Hemodynamic improvement in our patients is attributable to radical removal of deleterious effects of right ventricular congestion and associated tricuspid regurgitation on systemic venous return and left ventricular function. Although we did not exactly evaluate preoperative left ventricular function, echocardiography revealed a distortion of the left ventricular geometry caused by paradoxical motion of the interventricular septum in all patients. Previous clinical studies 22,23 in patients with isolated right ventricular volume overload indicated that late diastolic leftward displacement of the interventricular septum may impair distensibility and contractility of the left ventricle. In the setting of tricuspid regurgitation, compression of the left atrium by a distended right atrium and leftward bulging of the interatrial septum during right ventricular systole may decrease left atrial stroke volume and further reduce left ventricular filling. ${ }^{24}$ By means of complete decompression on the left heart, the total right ventricular exclusion procedure normalizes interventricular septal motion, increases left atrial volume, and subsequently achieves effective volume loading of the left ventricle.

Other beneficial effects of the right ventricular exclusion procedure are to relieve lung compression by the enlarged heart, as well as to make more space for the lung to expand. Despite long-lasting lung compression, all but one patient could be weaned from the ventilator within 24 hours after the operation. Adequate lung expansion may improve respiratory function and play an important role in successful univentricular circulation by reduction in pulmonary vascular resistance.

In conclusion, the total right ventricular exclusion pro- 
cedure is hemodynamically feasible if left ventricular function is well preserved. This procedure provides a definitive cure of ventricular tachycardia associated with arrhythmogenic right ventricular dysplasia, when the left ventricle is proved nonarrhythmogenic. Removal of a dilated right ventricle and downsizing the right atrium leads to effective decompression of the lung, as well as the left ventricle, and may result in more effective volume loading of a surgically created single ventricle. We believe this new surgical option offers rescue treatment for isolated congestive right ventricular failure in critically ill patients.

\section{References}

1. Marcus FI, Fontaine GH, Guiraudon G, et al. Right ventricular dysplasia: a report of 24 adult cases. Circulation. 1982;65:384-98.

2. Rossi PA, Massumi A. Arrhythmogenic right ventricular dysplasia: clinical features, diagnostic techniques, and current management. Am Heart J. 1982;103:415-20.

3. Fontaine G, Rougier FI, Tonet JL, et al. Electrode catheter ablation of resistant ventricular tachycardia in arrhythmogenic right ventricular dysplasia: experience of 13 patients with a mean follow-up of 45 months. Eur Heart J. 1989;10(suppl D):74-81.

4. Trappe H, Klein H, Fieguth H, Kielblock B, Wenzlaff P, Lichtlen PR. Clinical efficacy and safety of the new cardiovertor defibrillator systems. Pacing Clin Electrophysiol. 1993;16(suppl 2):153-8.

5. Guiraudon G, Fontaine G, Frank R, Leandri R, Barra J, Cabrol C. Surgical treatment of ventricular tachycardia guided by ventricular mapping in 23 patients without coronary artery disease. Ann Thorac Surg. 1981;32:439-50.

6. Misaki T, Watanabe G, Iwa T, et al. Surgical treatment of arrhythmogenic right ventricular dysplasia: long-term outcome. Ann Thorac Surg. 1994;58:1380-5.

7. Guiraudon G, Klein GJ, Gulamhusein SS, et al. Total disconnection of the right ventricular free wall: surgical treatment of right ventricular tachycardia associated with right ventricular dysplasia. Circulation. 1983;67:463-70.

8. Cox JL, Bardy GH, Damiano RJ Jr, et al. Right ventricular isolation procedures for nonischemic ventricular tachycardia. J Thorac Cardiovasc Surg. 1985;90:212-24.

9. Nimkhedkar K, Hilton CJ, Furniss SS, et al. Surgery for ventricular tachycardia associated with right ventricular dysplasia: disarticulation of right ventricle in 9 of 10 cases. J Am Coll Cardiol. 1992;19:107984.
10. Frank G, Lowes D, Baumgart D, et al. Surgical alternatives in the treatment of life-threatening ventricular arrhythmia. Eur J Cardiothorac Surg. 1988;2:207-16.

11. Guiraudon GM, Klein GJ, Sharma AD, Yee R, Guiraudon CM. Surgical therapy for arrhythmogenic right ventricular adiposis. Eur Heart J. 1989;10(suppl D):82-3.

12. Stark J, Kostelka M. The use of the right atrial flap in total cavopulmonary connection. J Card Surg. 1991;6:362-6.

13. Corrado D, Basso C, Thiene G, et al. Spectrum of clinicopathologic manifestations of arrhythmogenic right ventricular cardiomyopathy/ dysplasia: a multicenter study. J Am Coll Cardiol. 1997;30:1512-20.

14. Kumar AE, Flyer DC, Miettinen OS, Nadas AS. Ebstein's anomaly: clinical profile and natural history. Am J Cardiol. 1971;28:84-95.

15. Celermajer DS, Dodd SM, Greenwald SE, Wyse RK, Deanfield JE. Morbid anatomy in neonates with Ebstein's anomaly of the tricuspid valve: pathophysiologic and clinical implications. J Am Coll Cardiol. 1992;19:1049-53.

16. Anderson KR, Lie JT. The right ventricular myocardium in Ebstein's anomaly: a morphometric histopathologic study. Mayo Clin Proc. 1979;54:181-4.

17. Danielson GK, Driscoll DJ, Mair DD, Warnes CA, Oliver WC Jr. Operative treatment of Ebstein's anomaly. J Thorac Cardiovasc Surg. 1992;104:1195-202.

18. Carpentier A, Chauvaud S, Mace L, et al. A new reconstructive operation for Ebstein's anomaly of the tricuspid valve. J Thorac Cardiovasc Surg. 1988;96:92-101.

19. Chauvaud S, Fuzellier JF, Berrebi A, et al. Bi-directional cavopulmonary shunt associated with ventriculo and valvuloplasty in Ebstein's anomaly: benefits in high risk patients. Eur J Cardiothorac Surg. 1998;13:514-9.

20. Marianeschi SM, McElhinney DB, Reddy VM, Silverman NH, Hanley FL. Alternative approach to the repair of Ebstein's malformation: intracardiac repair with ventricular unloading. Ann Thorac Surg. 1998; 66:1546-50.

21. Starnes VA, Pitlick PT, Bernstein D, Griffin ML, Choy M, Shumway NE. Ebstein's anomaly appearing in the neonate: a new surgical approach. J Thorac Cardiovasc Surg. 1991;101:1082-7.

22. Lin SS, Reynertson SI, Louie EK, Levitsky S. Right ventricular volume overload results in depression of left ventricular ejection fraction: implications for the surgical management of tricuspid valve disease. Circulation. 1994;90(suppl 2):II209-13.

23. Hurwitz RA. Left ventricular function in infants and children with symptomatic Ebstein's anomaly. Am J Cardiol. 1994;73:716-8.

24. Louie EK, Bieniarz T, Moore AM, Levitsky S. Reduced atrial contribution to left ventricular filling in patients with severe tricuspid regurgitation after tricuspid valvulectomy: a doppler echocardiographic study. J Am Coll Cardiol. 1990;16:1617-24. 